\title{
El Museo Universitario de Antropología de la Utec: su importancia en una sociedad por culturizarse
}

Ramón D. Rivas

\section{¿Qué es un museo?}

En este país constatamos, en las últimas décadas, un creciente interés por la edificación de museos. Pero las preguntas que surgen son: ¿Sabemos lo que es un museo? ¿Sabemos para lo que sirve un museo? ¿Sabemos cuál es su finalidad principal? Hasta hace relativamente poco tiempo esas preguntas hubieran parecido absurdas; pero hoy el concepto clásico de museo esta en crisis. Las intensiones son buenas; pero cuando no partimos de conocimientos definidos y establecidos con base en estudios y lineamientos generales, basados en un consenso y en la teoría y práctica que nos ofrece la ciencia museológica, eso que creemos que es un museo a lo mejor no es más que una bodega de objetos. Las preguntas iniciales, que a la vez servirán de generadoras para esta presentación, son: ¿Qué es un museo? ¿Qué y cómo debe ser un museo?

No entraré en detalles sobre el término y el concepto clásico de museo. Sí es necesario mencionar que la palabra museo (del latín museum, que proviene a su vez de la griega mouseion, "casa de las musas") ha tenido, a lo largo de la historia, numerosas aplicaciones y significaciones hasta su sentido contemporáneo. La realidad y proyección sociocultural del museo actualmente constituye un fenómeno cada vez más relevante en nuestro entorno, que viene siendo estudiado por disciplinas científicas tan diversas como la antropología, la sociología, la pedagogía, la arquitectura o la historia del arte, entre tantas otras.

Si se tiene en cuenta la evolución del concepto de museo, en el contexto internacional, como una realidad dinámica que se ha ido transformando a través del tiempo, y que, por consiguiente, debe de incluir en la actualidad nuevas políticas culturales que apuestan por la protección, conservación y defensa 
del patrimonio mundial, las nuevas políticas estatales deberían apuntarle a un proceso de recopilación y construcción, de políticas culturales, con la intención de convenir una definición que se adecue a la realidad de los museos en el país.

No existe, en nuestro país, una política general de los museos. Los intentos por parte de los museos privados para una efectiva coordinación se han visto frustrados precisamente porque cada directivo de museo tiene su propia visión al respecto. En este país - como no hay directrices - cualquiera le puede poner el título de museo, a cualquier cosa, lo que naturalmente es incorrecto. En este sentido, las consideraciones que puedan estar presentes para definir una entidad museal se reconocerán a través de acuerdos entre sectores culturales y afines, que incluyan las siguientes nociones: la preservación del patrimonio y de las memorias; y los procesos de participación, inclusión, apropiación, reconocimiento, recuperación de identidad, educación y entretenimiento de la sociedad. Mientras se efectúe el consenso que precisa el desarrollo de la formulación participativa de una política nacional de museos, nos continua-

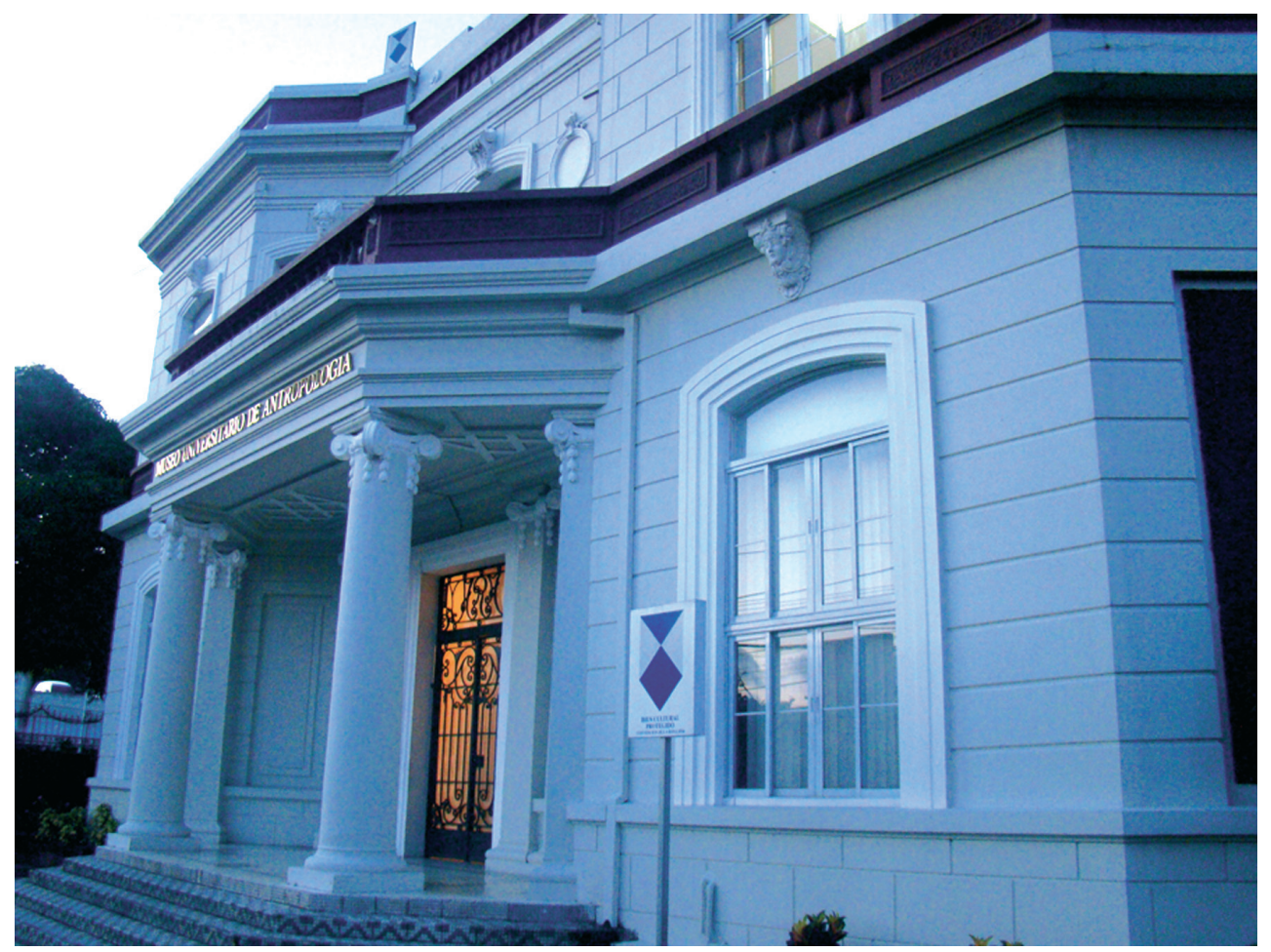

Entrada principal del Museo Universitario de Antropología, MUA, de la Utec 
remos adhiriendo a la definición del Concilio International de Museos (Icom, por sus siglas en inglés) Para esta instancia internacional, un museo

es una institución permanente, sin fines lucrativos, al servicio de la sociedad y de su desarrollo, abierta al público, y que efectúa investigaciones sobre los testimonios materiales del ser humano y de su medio ambiente, los cuales adquiere, conserva, comunica y exhibe, con propósitos de estudio, educación y deleite.

Para el mismo Icom, "esa definición de museo puede ser aplicada sin que surja limitación alguna a partir de la naturaleza del cuerpo directivo, el carácter territorial, la estructura funcional o la orientación de las colecciones de la institución en referencia". Pero también, el Icom plantea que "además de las instituciones designadas expresamente como 'museos', las siguientes también se califican como museos para los fines de esta definición”, así:

(I) los monumentos y sitios naturales, arqueológicos, etnográficos e históricos con carácter de museo, que adquieren, conservan y comunican testimonios materiales del ser humano y de su medio ambiente;

(II) las instituciones que mantienen y exhiben colecciones de especímenes vivos de plantas y animales, tales como jardines botánicos y zoológicos, acuarios y vivaria (viveros);

(III) los centros científicos y los planetarios;

(IV) galerías sin ánimo de lucro: los institutos de conservación y las galerías de exhibición mantenidas permanentemente por bibliotecas y centros de archivo;

(V) las reservas naturales;

(VI) las organizaciones de museos a escala internacional, nacional, regional o local, así como los ministerios y los departamentos o entidades públicas responsables de los museos, de acuerdo con la definición dada en este artículo;

(VII) las instituciones u organizaciones sin fines lucrativos que desarrollan programas de conservación, investigación, educación, entrenamiento, documentación y otras actividades relativas a los museos y la museología;

(VIII) los centros culturales y entidades que facilitan la preservación, perpetuación y administración del patrimonio cultural tangible e intangible (patrimonio vivo y actividades digitales creativas); 
(IX) otras instituciones tales que el Consejo Ejecutivo, después de revisar las recomendaciones del Comité Asesor, considere que contienen algunas o todas las características de un museo, o que apoyan la labor de museos y trabajadores profesionales de museos a través de la investigación museológica, la educación o la capacitación. ${ }^{1}$

Naturalmente, al leer y reflexionar sobre el precedente considero que es necesario conocer cuáles son las funciones y misiones propias de la entidad museo. Por ello es que la función del museo debe de centrarse principalmente en: coleccionar, investigar, conservar, comunicar y exhibir. Ahora, entre su misión debe de prevalecer el estudio, la educación y el deleite. Estos deberían ser los pilares fundamentales con los cuales nos debemos de sentir identificados cuando se hable de un museo.

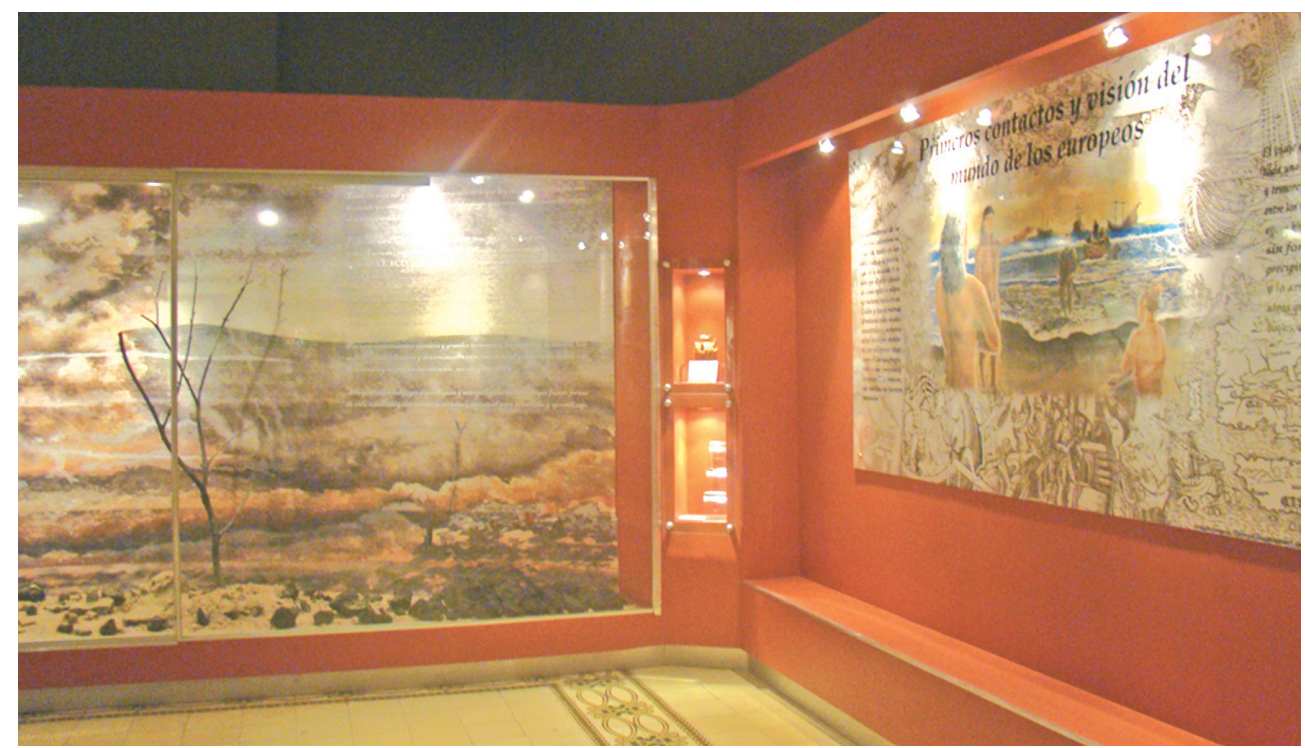

Sala permanente “Las migraciones”, MUA

\section{Un activismo cultural por parte del Estado que lleva a la necesidad de la conformación de una política cultural}

Y es que en la última década se constata, a lo largo y ancho de nuestra geografía nacional, un fuerte interés por parte de la población en conservar y mostrar

1 Definición y código de deontología del Icom para los museos. El Código de Deontología Profesional fue aprobado por unanimidad en la XV Asamblea General del Icom, que se celebró en Buenos Aires, Argentina, el 4 de noviembre de 1986, modificado en 2001 y revisado en octubre 2004 en Seúl, Corea del Sur. 
elementos del pasado, hecho impensable una o dos generaciones atrás. El deseo de encontrarse con la identidad se hace constante en todas las esferas de la sociedad. La gente en los pueblos y ciudades busca quién pueda escribir la historia del lugar; y otros toman esa responsabilidad por su propia cuenta. Hay interés por conocer la historia cultural que nos ha caracterizado; pero que muchas veces ni nosotros mismos conocemos.

El Estado, en alguna medida, ha demostrado el interés en la promoción de las diferentes manifestaciones culturales locales, creando para ello los espacios pertinentes nacionales y locales para la articulación de la sociedad salvadoreña, y, en este sentido, las casas de la cultura, con todos sus defectos, en muchos casos son un ente canalizador de estas iniciativas; pero queda claro que no han tenido ni las directrices generales ni específicas para la concretización de una buena labor cultural, que permee y vaya cimentando la identidad en esos lugares. Todo ha quedado en una especie de activismo cultural de paso. Y todo ello por el simple hecho de no poner en práctica una política cultural consensuada. Las políticas culturales que han existido se han limitado a fortalecer lo ya existente; y lo peor, a inventar cultura. Todas estas solo son intenciones y buenos deseos - pues así hay que verlo-, ya que si los que dirigen no presentan propuestas los que están abajo se las tienen que idear "para no quedar mal", se han manifestado en nuevos espacios de comunicación e iniciativas culturales.

No obstante, el interés por los museos es un hecho latente, y ya se han empezado a edificar agunos. Hoy por hoy el país cuenta con 23 de ellos, y los hay de diferentes temáticas y competencias. Ante esto, observamos que los museos tradicionales se han tenido que enfrentar a la competencia de las nuevas ofertas institucionales y privadas y a las demandas del público que los frecuenta.

Los museos han dejado de ser venerables almacenes de curiosidades y han tenido que enfrentarse a su renovación. Se establece, además, otra concepción sobre la finalidad de estos espacios. Empieza a quedar claro que los museos no tienen que ser - de ahora en adelante - muestras inertes del pasado, tienen que ser centros de actividad viva y permanente en las comunidades, de preservación de las diversas formas de cultura. Los museos tienen que ser para el pueblo, y no sólo para un grupo de privilegiados. No tienen que ser anticuados, tienen que ser centros de generación y proyección de conocimiento. 


\section{Hacia la conformación del Museo Universitario de Antropología de la Utec}

Con el Museo Universitario de Antropología - conocido por sus siglas como MUA - de la Universidad Tecnológica de El Salvador, se ha querido conformar un recinto para ver, reflexionar, y, a partir de los insumos que se presenten, planificar investigaciones. En definitiva, lo que se ofrece al público es lo que un grupo de profesionales en antropología y museología, por iniciativa del Dr. José Mauricio Loucel, rector de la Utec, han recreado. Son los remanentes que quedan de nuestra cultura que existió y persistió a lo largo de la historia para ser lo que ahora somos; y eso es lo que el museo presenta, algo así como una fotografía de colección para tener presente el pasado lejano y cercano. Para poder ver lo que fue y comparar con lo que ahora es. Eso es este museo, un espacio para observar y deleitarse; pero también un espacio para la reflexión. El museo induce a la investigación.

Por su estilo y la concepción que lo caracteriza, el MUA es una instancia dinámica en sus concepciones y contenidos, así como en su forma de accionar den-

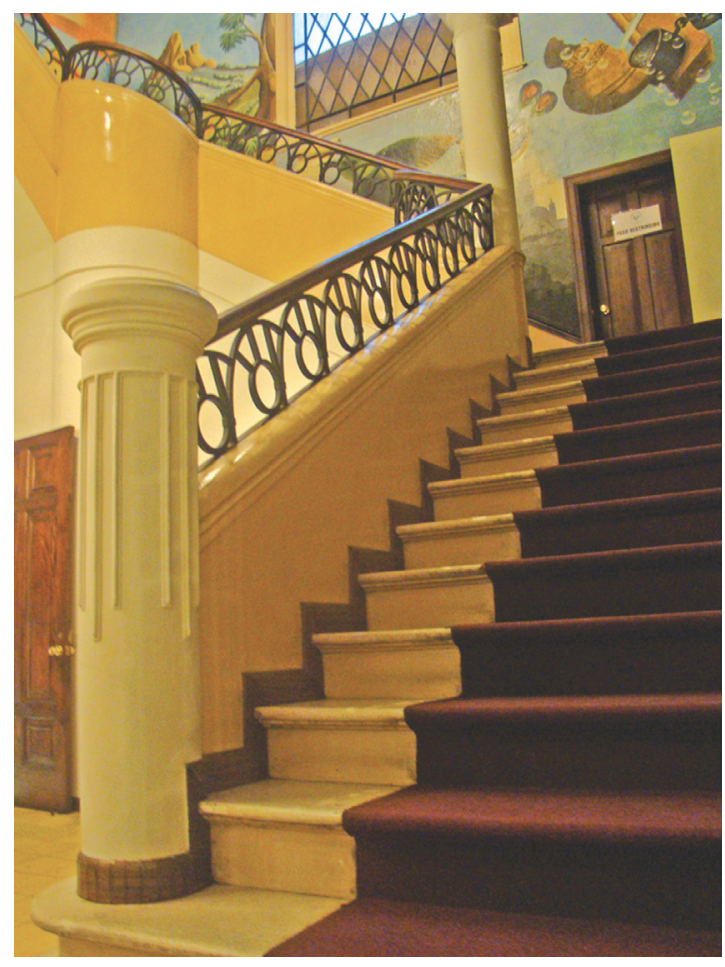

Detalle arquitectónico del MUA tro de la misma sociedad: ofrece conferencias, presentaciones de libros, se organizan foros, debates y a la vez los catedráticos de las ciencias arqueológicas y antropológicas pueden impartir sus clases teóricas en su recinto.

Por otra parte, considero de importancia mencionar que se constata a escala internacional $-\mathrm{y}$ nosotros lo reafirmamos en la práctica- que la mera conservación de los tesoros del pasado o la investigación especializada sobre estos ha dejado paso a los museos sin objetos; pero, también, con objetos del presente, producto de la mera persistencia; es decir, una com- 
binación entre pasado y presente. Los museos ahora pueden ser recreaciones del pasado, pero también del presente, y a su vez dar un indicio sobre como se avizora el futuro. El diseño de las salas y las muestras museográficas del museo lo confirman. Lo recalco, los museos ya no son solo espacios para guardar objetos antiguos.

La otra cuestión es también que - a mi juicio - la mayor parte de los museos actuales, consciente o inconscientemente, generan situaciones educativas no formales. Este tipo de educación, materializada en un conjunto de

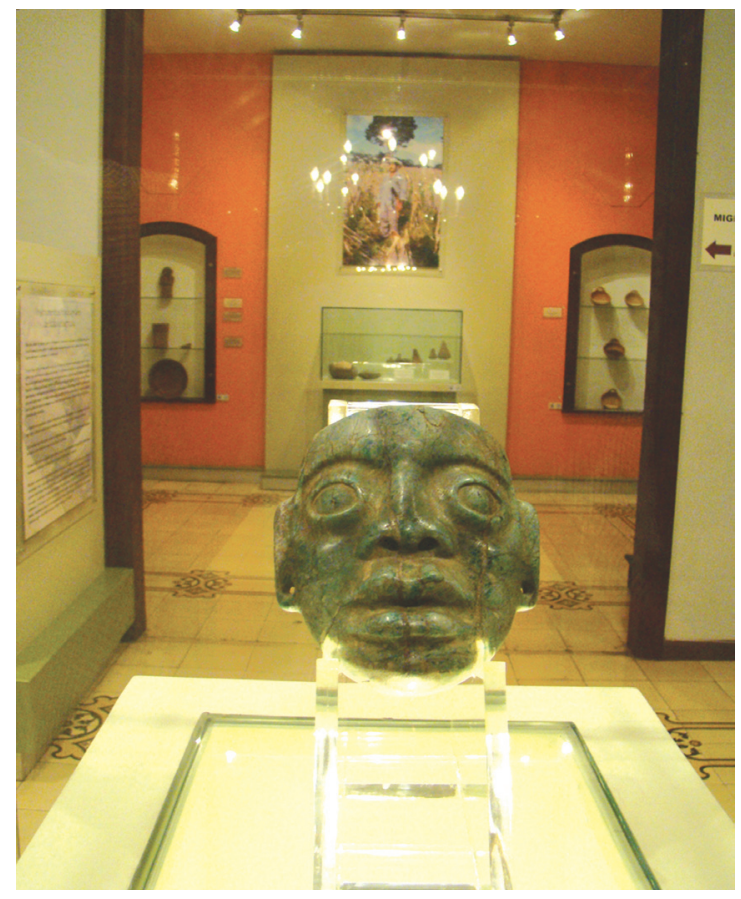

Máscara de jade, Sala permanente del MUA objetivos educativos y de actuaciones destinadas a alcanzarlos, es la forma propia de educación de los museos. Pero la cuestión es que en nuestra sociedad la manifestación de las políticas de educación se ha centrado, a lo largo de la historia, más que todo a un tipo de educación "bancaria" y muchas veces irreflexiva, dejando de lado la reflexión y lo lúdico-generativo que, si bien ha estado presente, solo ha sido para una elite cultural y no un libro abierto para todos.

El MUA es una iniciativa particular que, con el solo hecho de su existencia, contrarresta la ausencia de políticas urbanísticas efectivas en la ciudad capital y a la vez se convierte en un espacio abierto que atiende las necesidades culturales y lúdicas de la población estudiantil y capitalina. El MUA ha sido el primer museo en su categoría que se ha abierto espacio en el mismo centro histórico capitalino, zona que por muchos ha sido considerada como del mal vivir; y la realidad ha demostrado, en los cuatro años de existencia del museo, que hay un interés latente por parte de la población en este tipo de espacios culturales. El MUA es, por lo tanto, un espacio de reflexión e interacción social en el que la investigación del patrimonio nacional juega un papel de primer orden. 
Es por ello que los lineamientos generales del MUA se han concretizado de la siguiente manera:

- El museo es un espacio de interacción y reflexión comunitaria para que los estudiantes y la comunidad no estudiantil conviertan en un referente, para la discusión de temas relacionados con las identidades y su fortalecimiento. En este sentido, el museo es ya un espacio en donde se generan discusiones en torno al pasado y el presente de la sociedad salvadoreña, se promueve la investigación histórico-cultural de nuestro país con temas que contribuyen a la formación de los estudiantes de las carreras de Antropología, Arqueología e Historia de la universidad. El museo, por su dinámica, fortalece de manera descentralizada las políticas culturales del Estado salvadoreño, mediante la interacción que juega en la promoción de los valores de identidad.

- El museo es ya un instrumento para relativizar nuestras costumbres, comportamientos y creencias, para contribuir a la reflexión sobre nuestra realidad social y cultural, con el único objetivo de conocer para educarnos y así disponer del conocimiento y criterio necesarios para formular planes a futuro, para aprender a cuidar y valorar lo que la sociedad posee pero no conoce.

\section{Función sociocultural y científica del MUA}

El Museo Universitario de Antropología nace como una institución dedicada a la difusión del pensamiento científico-antropológico y también a la conservación y difusión del patrimonio cultural salvadoreño, reflejado en las colecciones que presentan sus salas de exhibición permanente y temporal, y, además, las muchas actividades culturales que se desarrollan. La naturaleza de las exposiciones en variada, y sobresale el acervo ancestral en todos los aspectos en los que es rico El Salvador. El MUA es, en primera instancia, para que los estudiantes de las carreras de la cultura puedan tener un referente para profundizar en sus investigaciones, pero también para el disfrute de la sociedad en general. Sus múltiples actividades dan testimonio de ello.

Los estudiantes de antropología, arqueología, diseño gráfico y ciencias de la comunicación han encontrado en el MUA un referente, y allí realizan sus horas sociales. Como toda institución con deseos de servir a la sociedad, el 


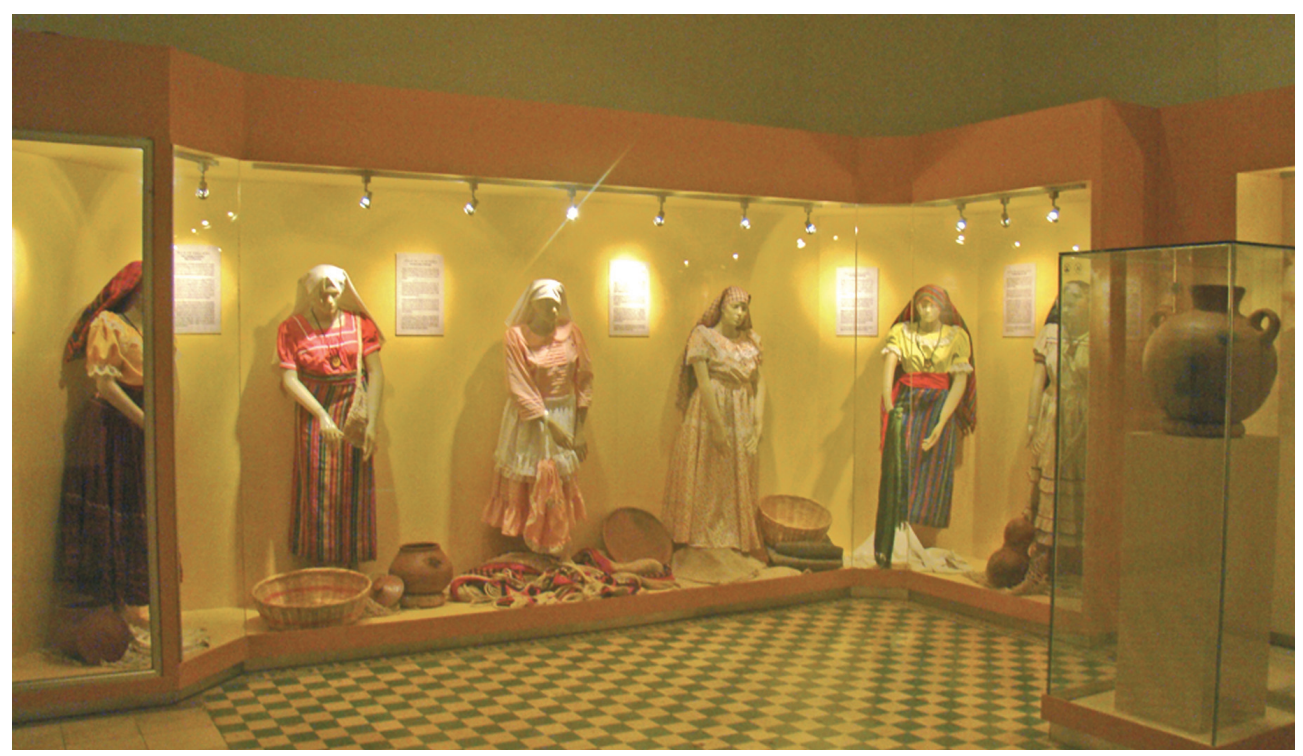

Sala permanente "persistencia de un pasado", MUA

MUA proyecta su razón de ser por medio de su visión y misión. El museo es un espacio cultural en el que estudiantes y público en general conocen la rica y variada museografía de naturaleza histórica y antropológica que resguarda en sus recintos. Para una mejor comprensión, el MUA está distribuido en cinco salas de exhibición permanente conceptualizadas así:

- Sala que presenta la persistencia del pasado y la etnografía salvadoreña.

- Sala dedicada como tributo al cantautor nacional don Francisco Antonio Lara Hernández, mejor conocido como Pancho Lara.

- Sala "Instrumentos tradicionales de producción agrícola".

- Sala "Las migraciones".

- Sala de exhibiciones temporales.

- Auditórium de usos múltiples.

\section{Explicación del contenido de las salas}

La historia cultural que el MUA conserva - y que lo hace único en su género, como decíamos - abarca un período de 21.000 años. Dentro de su rico acervo cultural encontramos colecciones de carácter arqueológico, etnográfico e histórico, conformando una variada colección de objetos representativos de la cultura mesoamericana y nacional, que reflejan el devenir histórico y sociocultural desde tiempos ancestrales hasta la actualidad. 
La colección arqueológica exhibida es de cerca de 200 piezas, y en ella encontramos algunas muy antiguas, como una figurilla bolina datada en el período preclásico tardío (400 a.C a 300 d.C.), una considerable cantidad de piezas procedentes del período clásico (350-900 d.C.) en las que destacan vasos y cajetes de distintos estilos cerámicos, como el copador, el salúa, el chalate tallado, el gualpopa, el polícromo campana, el guarumal y otros. Son piezas arqueológicas que representan diferentes distintivos por el uso de cierta iconografía que reflejaba las creencias religiosas de los pueblos que habitaron Mesoamérica.

Dentro de la colección de etnografía encontramos una serie de objetos de producción artesanal, objetos ya casi desaparecidos, que de alguna forma reflejan la idiosincrasia del pueblo salvadoreño a través de la creatividad del artesano, incluyendo indumentaria regional en la que podemos apreciar los resabios indígenas de la época prehispánica y actual, así como la modificación de estos patrones estéticos por la inclusión de los cánones traídos por los españoles a estas tierras.

La exhibición permanente dedicada al cantautor nacional Pancho Lara rescata una serie de piezas de importante valor histórico: partituras, publicaciones,

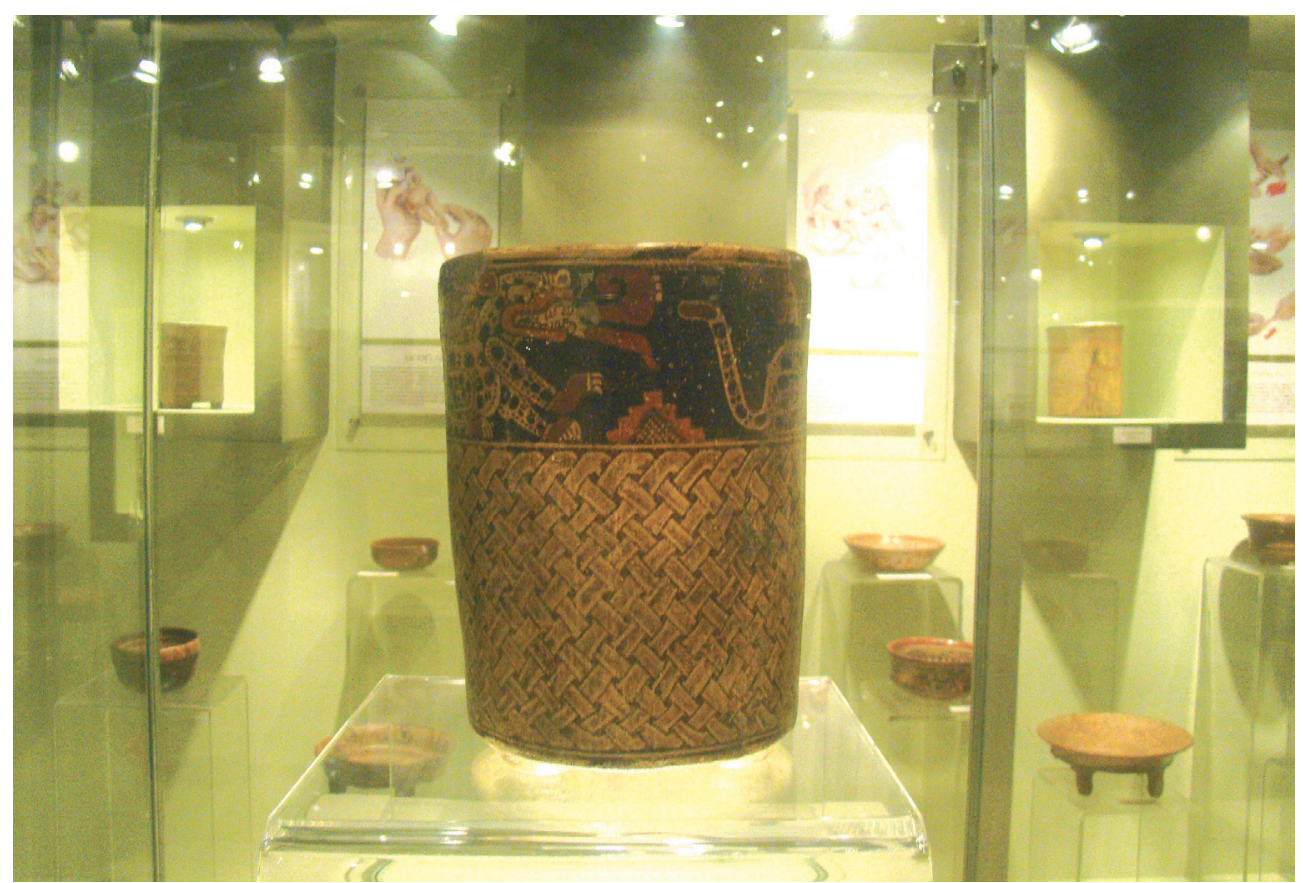

Vaso Salúa en exposición en una de las salas arqueolgógicas del MUA. 
instrumentos y objetos de uso personal del artista que, en su día, compuso muchas canciones en donde se advierte el sabor rural así como la sencillez de su pueblo. Lara es el compositor de una de las canciones más emblemáticas de la cultura salvadoreña: "El carbonero".

La sala "Instrumentos tradicionales de producción agrícola" recoge una colección de objetos, tanto prehispánicos como actuales, que ponen de manifiesto las técnicas tradicionales utilizadas en la producción agrícola desde aquella época hasta el día de hoy. Cabe decir que, a pesar de la importancia del arado, introducido por los españoles durante el período colonial, muchas de las antiguas técnicas de cultivo, que datan de antes de la Conquista, aún son utilizadas por el actual campesino salvadoreño. Así, observamos en la exposición chuzos, tecomates, arados, yugos, machetes, aparejos, entre otros; y semillas de los cultivos autóctonos e importados, que han sido parte de la historia de este país.

La exhibición permanente dedicada a las migraciones humanas en El Salvador demuestra que, desde tiempos prehispánicos hasta la actualidad, los desplazamientos humanos en forma sucesiva a causa de los eventos de naturales en la forma de erupciones volcánicas, terremotos y huracanes, entre otros; así como las guerras, golpes de estado o ingerencias políticas... son los factores que han trasformado nuestro rostro cultural desde tiempos inmemoriales. Dicha exposición ofrece material arqueológico, histórico y multimedia, cuya temática gira en torno a las movilizaciones humanas en esta parte del mundo.

En el espacio de exhibiciones temporales se muestra, de manera transitoria y de acuerdo con un programa previamente diseñado, una serie de exposiciones temporales de temática variada, que van desde antropológicas, arqueológicas hasta históricas de las artes, con la finalidad de renovarse constantemente y ofrecer siempre al visitante, tanto docente, estudiantes como particulares, nuevas exposiciones de carácter científico y artístico. Además, el MUA cuenta con un auditórium de usos múltiples en el que se desarrollan una serie de actividades académicas y de divulgación científica y artística, programas de conferencias, proyecciones documentales, entre otros.

Sin más, las diversas actividades que se llevan a cabo hacen de este espacio cultural una institución viva, y, a la par de los intereses de su público y de las nuevas tendencias tecnológicas, hacen del espacio un museo de convergencia, entretenimiento y deleite. 


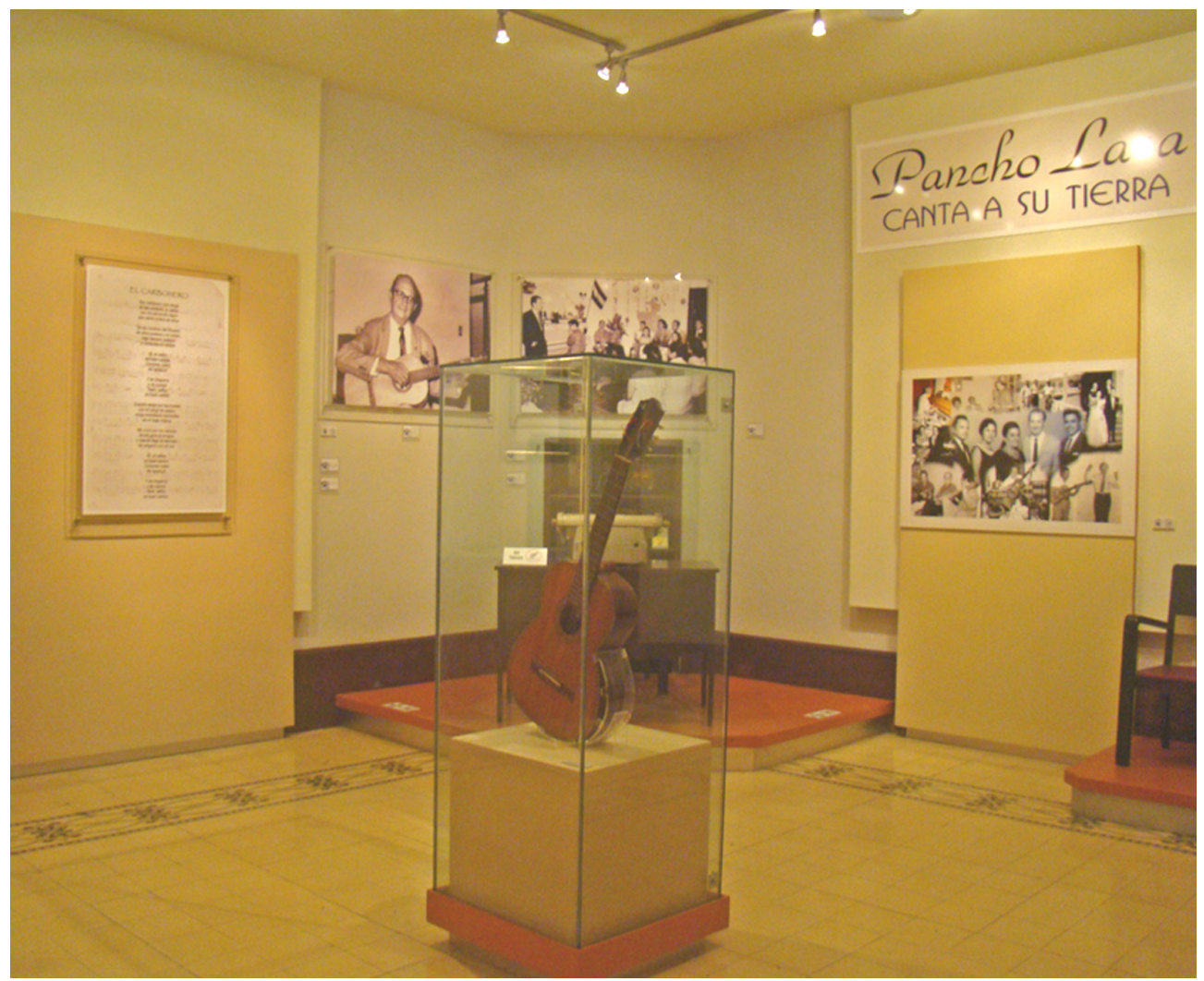

Sala dedicada al cantautor Pancho Lara, ubicada en la segunda planta del MUA

\section{A manera de consideración final}

De lo precedente, y conociendo la realidad del país, soy de la opinión que es necesario concientizar e incentivar a la realización de estudios del público en lo referente al papel, interés e importancia de los museos. Sería digno que cada uno de los museos del país - y me refiero a los ya constituidos como tales - iniciara sus estudios de visitantes de acuerdo a sus intereses e inquietudes y, concretamente, en lo referente a los perfiles, colecciones, objetivos, metas y preferencias. Solo de esta forma, en un país que se inicia en esta tan importante herramienta de conocimiento y difusión de la cultura, puede tener insumos de lo que verdaderamente siente y quiere al gente.

Es por ello que las instancias pertinentes del Estado deberían de iniciar un programa regular de estudios de consumo cultural cuantitativo y cualitativo, a fin de orientar programas coordinados con los museos privados que cada 
vez parecen tener más auge. En este sentido, la definición de un programa tendiente a desarrollar la formación de recursos humanos en el área sería una herramienta fundamental. En este país esta es un área prácticamente desconocida.

Estoy seguro de que el contacto con diferentes centros de investigación de consumo cultural - privados y estatales, que no son muchos - facilitaría la creación de programas conjuntos de investigación y análisis en temas de importancia para la nación y, sobre todo, en un país como el nuestro en donde nunca ha habido un proyecto de nación y, por ende, de cultura. Dentro de este proyecto, invitar a especialistas extranjeros permitiría mostrar las experiencias e investigaciones desarrolladas por ellos y establecer vínculos de trabajo más productivos. El MUA nos está enseñando que es importante la organización de actividades que muestren el acervo cultural, del que es rico el país, ya que con esto se educa el pueblo y, por ser un museo universitario, se motiva a los estudiantes para el desarrollo de investigaciones específicas.

\section{Referentes bibliográficos}

AA. VV, Los museos en el mundo. Barcelona, Salvat Editores; Lausanne, Éditions Grammmont, S.A., Biblioteca Salvat de Grandes Temas. 1993.

Aiyaoan, A., y Satyamurti, S., Handbook of Museum Technique, Madrás. 1960.

Fernández, L., Museología. Introducción a la teoría y práctica del museo. Ediciones Istmo. Madrid, España. 1993.

Museo Universitario de Antropología, MUA, Utec. Catálogo. San Salvador, septiembre, 2008.

León, Aurora, El museo. Teoría, praxis y utopía. Ediciones Cátedra. España. 1999.

Rivas, Ramón, Ensayo sobre estudios antropológicos en El Salvador. [Digital]. Documento inédito en proceso de publicación. El Salvador. 2009. 


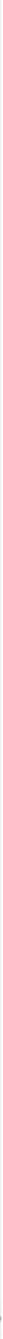

